\title{
Apophysomyces jiangsuensis sp. nov., a Salt Tolerant and Phosphate-Solubilizing Fungus from the Tidelands of Jiangsu Province of China
}

\author{
Siyu Li ${ }^{1,2}$, Ruiming Han ${ }^{1,3}$, Huanshi Zhang ${ }^{4}$, Yongchun Song ${ }^{5}$, Fugeng Zhao ${ }^{1}$ and Pei Qin ${ }^{1, *}$ \\ 1 Halophyte Research Lab, Nanjing University, Nanjing 210008, China; 32029@qzc.edu.cn (S.L.); \\ ruiming.han@njnu.edu.cn (R.H.); fgzhao@nju.edu.cn (F.Z.) \\ 2 Qu Jiang Experimental Middle School, Quzhou 324022, China \\ 3 Jiangsu Center for Collaborative Innovation in Geographical Information Resource Development and \\ Application, Jiangsu Key Laboratory of Environmental Change and Ecological Construction, \\ School of Environment, Nanjing Normal University, Nanjing 210023, China \\ 4 Nanjing Institute for Comprehensive Utilization of Wild Plants, Nanjing 210042, China; \\ zhanghuanshi@126.com \\ 5 Institute of Functional Biomolecules, Nanjing University, Nanjing 210093, China; songych@nju.edu.cn \\ * Correspondence: qinpei@nju.edu.cn; Tel.: +86-25-139-5196-6461
}

Received: 24 October 2020; Accepted: 24 November 2020; Published: 26 November 2020

\begin{abstract}
A newly isolated phosphate-solubilizing fungus from the topsoil of Spartina alterniflora habitats in Yancheng coastal salt marsh was cultivated. Scanning electron microscopy observation revealed that the sporangia are nearly spherical, peach-shaped, and the spores formed on the top of sporangia. The spores are ellipsoidal with raised white nubbins on the surface. Based on a polyphasic study and the genetic distance analysis referring to the sequence analysis of ITS (ITS1 + 5.8S + ITS2) and $28 \mathrm{~S}$ rDNA (D1/D2 domains) genes, the novel species belongs to the genus Apophysomyces and is named as $A$. jiangsuensis. The optimum growth temperature and salinity of the new species were $28{ }^{\circ} \mathrm{C}$ and $1.15 \% \mathrm{NaCl}$, respectively. A study of its phosphate-solubilizing ability revealed that the fungus had an obvious decomposition effect on lecithin, $\mathrm{Ca}_{3}\left(\mathrm{PO}_{4}\right)_{2}$, and $\mathrm{AlPO}_{3}$, respectively. The $\mathrm{pH}$ of the fermented liquid progressively decreased from 6.85 to 2.27 after 7 days of incubation, indicating that the low molecular weight organic acids excreted into the culture liquor were oxalic, succinic, and malic acids and a trace amount of citric acid. Among these, oxalic acid was the major organic acid, and its amount reached $652.5 \mathrm{mg} / \mathrm{L}$. These results indicated that the main mechanism underlying the dissolved phosphorus was related to the secretion of large amounts of organic acids.
\end{abstract}

Keywords: Apophysomyces; taxonomy; phosphorus-dissolving; soil fungi

\section{Introduction}

The genus Apophysomyces was first proposed by Misra et al. (1979) and A. elegans was the type specimen that was isolated and identified in the soils in Northern India [1]. Apophysomyces belongs to the order Mucorales and Benny et al. (2001) identified it as a genus in the family Mucoraceae based predominantly on morphology [2], while Hoffmann et al. (2013) put it into Saksenaeaceae based on a phylogenetic analysis of four molecular markers [3]. Meanwhile, Wijayawardene et al. (2020) confirmed that Apophysomyces was contained in Saksenaeaceae on the basis of phylogeny of the kingdom Fungi [4].

The characteristics of the type species A. elegans include pyriform sporangia, conspicuous funneland/or bell-shaped apophyses, and subhyaline, thin-, smooth-walled, and oblong sporangiospores that terminate in a columellate, multispored sporangium [1]. Additionally, it is pretty thermotolerant 
that can grow rapidly between 26 and $42{ }^{\circ} \mathrm{C}$ [5]. Apophysomyces is usually found in soil, decaying vegetation, and detritus, which has been reported to cause severe human infections that is more common in tropical and subtropical regions $[1,6]$. The type species A. elegans has been reported as an agent of zygomycosis in immunocompromised patients [7,8]. The method of combining molecular biology and morphological characteristics was used by Alvarez et al. (2010), and three species were identified, namely, A. ossiformis, A. trapeziformis, and A. variabilis [9]. A. mexicanus was isolated from an infected car accident patient and shown to have caused the disease, according to Bonifaz et al. [10]. A. thailandensis, which can solubilize metal minerals, was isolated from soil in Chiang Mai Province, Thailand [11]. Six species of the Apophysomyces have been discovered thus far, all of which failed to sporulate on routine mycological media [9-11].

Soil phosphorus is among the crucial limiting factors in agricultural practices. About $43 \%$ of the world's 1.319 billion ha of arable land is phosphorus-deficient [12]. Phosphate-solubilizing microorganisms (PSMs) refer to the functional group of microorganisms that can transform insoluble soil phosphate into soluble phosphorus in the course of their living activities $[13,14]$. PSMs dissolve poorly soluble mineral phosphates in soil through various processes, such as acidification, proton exchange, chelation, and enzymatic hydrolysis [15]. The efficiency to solubilize rock phosphate (RP) by Trichoderma and Aspergillus strains depends on the release of organic acids with low acidity constants and it is irrelevant to the concentration when they are released. It can be raised that the production of organic acids is the main mechanism of RP dissolution [16]. In our previous work, a formula derived from the mixture of arbuscular mycorrhizal fungi (Glomus mosseae) and mucoroid fungus (A.jiangsuensis) proved that a valid P-solubilizing agent could increase the content of available phosphorus in saline lands. Results showed that certain fungal strains could be promising tools to improve the utilization of saline soil phosphorus resources [17]. Further investigation revealed that although AM fungal hyphae were hampered in terms of colonization capacity, spore germination, and growth by salinity, $\mathrm{NaCl}$ promoted certain PSM (A. jiangsuensis) populations in the rhizosphere of saline crops, and PSM abundance was correlated positively with plant growth and shoot phosphorus concentration [18]. Considering the extreme importance of $P$ nutrition in saline agriculture, it is important to isolate and identify cryptic salt-tolerant P-solubilizing fungi species.

The objectives of present work were as follows: (i) to describe salt tolerant P-solubilizing fungus Apophysomyces jiangsuensis as a new species, isolated from the topsoil of S. alterniflora habitats in Jiangsu tideland, China, based on the results of a phylogenetic study and the genetic distance analysis referring to the sequence analysis of ITS and 28S rDNA genes, and to evaluate its morphological characteristics; (ii) to supply a method to stimulate the production of spores; and (iii) to study the phosphate-solubilizing ability and preliminarily explore the P-solubilizing mechanisms of the new species.

\section{Materials and Methods}

\subsection{Fungal Strain}

The fungal strain studied in the present work was isolated from the surface soils collected from Jiangsu Yancheng Wetland National Nature Reserve of Rare Birds. From three soils samples collected from the mudflat of Spartina alterniflora $\left(33^{\circ} 36^{\prime} \mathrm{E}, 120^{\circ} 36^{\prime} \mathrm{N}\right)$, an identical strain was isolated and preserved in the HrLab (Halophyte Research Lab) of Nanjing University before the present study. The individual strains were denoted as Mucoraceae sp. SM-1 as the laboratory serial no. and finally named A. jiangsuensis. The holotype was preserved by China General Microbiological Culture Collection Center (CGMCC) and given the preservation No. CGMCC3.17001, simultaneously, lyophilized formats were stored at $-20^{\circ} \mathrm{C}$ in the HrLab of Nanjing University. 


\subsection{Morphological Studies and Growth Observation}

The strain was subcultured on the following: modified Martin agar medium (MAM) comprising $\mathrm{K}_{2} \mathrm{HPO}_{4}(1 \mathrm{~g}), \mathrm{MgSO}_{4} \cdot 7 \mathrm{H}_{2} \mathrm{O}(0.5 \mathrm{~g}), \mathrm{NaCl}(11.5 \mathrm{~g})$, agar (20 g), peptone (5 g), glucose (10 g), gelose (10 g), and distilled water $(1000 \mathrm{~mL})$; PDA; Sabouraud dextrose agar (SDA) comprising glucose (4 g), peptone (10 g), agar (20 g), $\mathrm{NaCl}$ (11.5 g), and distilled water (1000 mL); Czapek agar (CZA, Difco, Becton Dickinson, France); millet extract agar (MEA) comprising millet extract (10 g), agar (20 g), $\mathrm{NaCl}(11.5 \mathrm{~g})$, and distilled water $(1000 \mathrm{~mL})$; and oat medium agar (OMA) comprising oat meal (17 g), agar (20 g), $\mathrm{NaCl}(11.5 \mathrm{~g})$, glucose (2 g), sucrose (3 g), and distilled water (1000 mL). The strain was incubated in the dark at $28^{\circ} \mathrm{C}$ for 9 days. Superficial characteristics, color, edge feature, colony diameter, and time cost for the full coverage of the fungal colonies were documented daily. Three replicates were made in each test.

\subsection{Optimum Growth Temperature and Salt Concentration}

The strain was subcultured on MAM at $10^{\circ} \mathrm{C}, 20^{\circ} \mathrm{C}, 24^{\circ} \mathrm{C}, 28^{\circ} \mathrm{C}, 32{ }^{\circ} \mathrm{C}, 37^{\circ} \mathrm{C}$, and $42{ }^{\circ} \mathrm{C}$ then cultured in the dark at for 4 days. The strain was grown on Martin broth medium comprising $\mathrm{K}_{2} \mathrm{HPO}_{4}$ $(1 \mathrm{~g}), \mathrm{MgSO}_{4} \cdot 7 \mathrm{H}_{2} \mathrm{O}(0.5 \mathrm{~g})$, peptone $(5 \mathrm{~g})$, glucose $(10 \mathrm{~g})$, gelose $(10 \mathrm{~g})$, and distilled water $(900 \mathrm{~mL})$, to which $0.8 \%, 1.0 \%, 1.15 \%, 1.3 \%, 1.5 \%$, and $1.8 \% \mathrm{NaCl}$ was added. The inoculation dose was $2 \%$. Then, the strain was placed on a shaker in the dark for $72 \mathrm{~h}$ at $180 \mathrm{rpm}$ and $28{ }^{\circ} \mathrm{C}$. The dry weight of mycelium was recorded. The salinity condition that yielded the maximum biomass was selected as the salinity condition for the subsequent experiments. Three replicates were made in each test.

\subsection{The Specific Method of Inducing Sporulation}

Apophysomyces species failed to sporulate on routine mycological media [19]. To reliably and consistently obtain sporulation, the A. jiangsuensis was cultured in a wide-mouthed glass bottle on millet and bran solid medium (MBM) comprising millet $(7.5 \mathrm{~g})$, two drops of sesame oil, and $15 \mathrm{~mL}$ of liquid. The liquid consisted of yeast extract $(0.5 \mathrm{~g})$, sodium tartrate $(0.1 \mathrm{~g})$, sodium glutamate $(0.1 \mathrm{~g})$, $\mathrm{FeSO}_{4} \cdot 7 \mathrm{H}_{2} \mathrm{O}(0.01 \mathrm{~g})$, and distilled water $(15 \mathrm{~mL})$. Distilled coverslips were embedded in a $45^{\circ}$ angle into MBM inoculated with the fungal strain. Coverslips were placed perpendicularly to the trace line of inoculation. Wide-mouthed glass bottles were then cultured at $28 \pm 1^{\circ} \mathrm{C}$ until the mycelium grew and covered the coverslips, which were carefully processed for observation with an optical microscope and photographed. When mycelia on the coverslips began to turn yellow, they were examined by scanning electron microscopy (SEM) and optical microscopy.

\subsection{DNA Extraction, Amplification, and Sequencing}

DNA was extracted and purified directly from fungal colonies following a slightly modified fast DNA kit protocol (Bio101, Vista, CA, USA) that consisted of a homogenization step repeated thrice with a Fast Prep FP120 instrument (Thermo Savant, Holbrook, NY, USA). DNA was quantified by the GeneQuant pro (Amersham Pharmacia Biotech, Cambridge, UK). The internal transcribed spacer (ITS) region of the nuclear rDNA was amplified using the primer pair ITS5-ITS4 and the D1-D2 domains of the 28S rDNA gene were amplified using the primer pair NL1-NL4 (Zhang and Su 2006). The PCR mixture $(25 \mu \mathrm{L})$ contains $1.5 \mu \mathrm{L}$ of template DNA, $10 \mathrm{mM}$ Tris- $\mathrm{HCl}(\mathrm{pH} 8.3), 50 \mathrm{mM} \mathrm{KCl}$, $2.5 \mathrm{mM} \mathrm{MgCl}_{2}$ (10× Perkin-Elmer buffer II plus $\mathrm{MgCl}_{2}$ solution Roche Molecular Systems, Branchburg, NJ, USA), $100 \mathrm{mM}$ of each dNTP, $1 \mathrm{mM}$ of each primer, and $1.5 \mathrm{U}$ of Ampli Taq DNA polymerase (Roche). The amplification program for the three DNA fragments included an initial denaturation at $94{ }^{\circ} \mathrm{C}$ for $5 \mathrm{~min}$, followed by 28 cycles of denaturation at $95^{\circ} \mathrm{C}$ for $30 \mathrm{~s}$, annealing for $1 \mathrm{~min}$ at $54{ }^{\circ} \mathrm{C}$, and extension for $1 \mathrm{~min}$ at $72{ }^{\circ} \mathrm{C}$, ending with $5 \mathrm{~min}$ at $72{ }^{\circ} \mathrm{C}$. The products were purified with an Illustra GFXTM PCR DNA and Gel Band Purification Kit (General Electric Healthcare, Buckingham shire, UK) and stored at $-20{ }^{\circ} \mathrm{C}$ until sequencing. PCR products were sequenced using the same primers used for amplification and following the Taq Dye Deoxy Terminator Cycle Sequencing Kit 
protocol (Applied Biosystems, Gouda, The Netherlands). Reactions were run on a 310 DNA sequencer (Applied Biosystems, Gouda, The Netherlands). Consensus sequences were obtained using the Auto assembler program (Perkin-Elmer-Applied Biosystems) and Seqman software (Laser-gene, Madison, WI, USA).

\subsection{Phylogenetic Analysis}

Multiple sequence alignments with reference sequences of Apophysomyces strains were performed using CLUSTAL X 2.1 [20]. Details of the sequences used for phylogenetic analysis are provided in Table 1. The alignment was checked and manually modified in GENEDOC [21] to remove the extra $5^{\prime}$ and $3^{\prime}$ sequences from where the sequences were overlapped. The combined alignments were deposited in TreeBase (http://treebase.org/treebase-web/home.html, submission ID: 27044). Phylogenetic analyses were conducted by Bayesian inference (BI) and maximum likelihood (ML) analyses using MrBayes v.3.2.6 [22] and IQ-TREE v.1.6.3 [23], respectively. jModelTest 2.1.10 [24] was used to compare the likelihood of the different nested models of DNA substitution and to select the best-fit model for the dataset through Akaike information criterion (AIC). BI analysis was performed using a Markov chain Monte Carlo (MCMC) algorithm. There were 5,000,000 generations that resulted in 50,000 trees for sampling every 100 generations. The first 12,500 trees (the first $25 \%$ was sampled by default in the software) were discarded as the burn-in phase, and the remaining 37,500 trees were used to calculate posterior probabilities (PP) values in the majority rule consensus tree. In ML analysis, we obtained branch supports with the ultrafast bootstrap [25] implemented in the IQ-TREE. The pairwise genetic distances (p-distance) were calculated using MEGA version 6 [26] with substitutions: Transitions + Transversions.

Table 1. The strains used in this study and their GenBank accession numbers.

\begin{tabular}{|c|c|c|c|c|c|}
\hline \multirow[t]{2}{*}{ Species } & \multirow[t]{2}{*}{ Isolate } & \multirow[t]{2}{*}{ Source } & \multicolumn{3}{|c|}{ GenBank Accession No. } \\
\hline & & & ITS & $28 S$ & Reference \\
\hline A. variabilis & UTHSC 06-4222 & Dolphin, Bahamas & FN556428 & FN554255 & [9] \\
\hline A. variabilis & IMI 338333 & Daly river, Australia & FN556439 & FN554256 & [9] \\
\hline A. variabilis & IMI 338332 & Ankle aspirate, Australia & FN556438 & FN554257 & [9] \\
\hline A. variabilis & GMCH 480/07 & Cutaneous infection, India & FN556442 & FN554253 & [9] \\
\hline A. variabilis & CBS 658.93 & Osteomyelitis, Netherlands Antilles & FN556436 & FN554258 & [9] \\
\hline A. trapeziformis & UTHSC R-3841 & Necrotic face tissue, GA, USA & FN556434 & FN554263 & [9] \\
\hline A. trapeziformis & UTHSC 08-2146 & Skin biopsy, CO, USA & FN556430 & FN554260 & [9] \\
\hline A. trapeziformis & UTHSC 08-1425 & Abdominal tissue, PHA, USA & FN556429 & FN554261 & [9] \\
\hline A. trapeziformis & UTHSC 06-2356 & Dolphin, TX, USA & FN556427 & FN554262 & [9] \\
\hline A. ossiformis & UTHSC 07-204 & Facial cellulitis, AZ, USA & FN556435 & FN554251 & [9] \\
\hline A. ossiformis & UTHSC 04-838 & Cellulitis wound leg, MN, USA & FN556432 & FN554252 & [9] \\
\hline A. mexicanus & CBS 136361 & Human, Mexican & HG974255 & HG974256 & [10] \\
\hline A. elegans & CBS 477.78 & Soil, Gorakhpur, India & FN556437 & FN554250 & [9] \\
\hline A. elegans & CBS 476.78 & Soil, Deoria, India & FN556440 & FN554249 & [9] \\
\hline A. jiangsuensis & CGMCC3.17001 & Soil, JiangSu, China & KF048102 & KF055451 & This study \\
\hline
\end{tabular}

\subsection{Dissolved Phosphorus Ability}

Liquid medium formulation: glucose $10 \mathrm{~g}$, $\left(\mathrm{NH}_{4}\right)_{2} \mathrm{SO}_{4} 0.5 \mathrm{~g}, \mathrm{MgSO}_{4} \cdot 7 \mathrm{H}_{2} \mathrm{O} 0.3 \mathrm{~g}, \mathrm{NaC} 111.3 \mathrm{~g}$, $\mathrm{KCl} 0.3 \mathrm{~g}, \mathrm{FeSO}_{4} \cdot 7 \mathrm{H}_{2} \mathrm{O} 0.03 \mathrm{~g}, \mathrm{MnSO}_{4} \cdot 7 \mathrm{H}_{2} \mathrm{O} 0.03 \mathrm{~g}$, and distilled water $1000 \mathrm{~mL}$. Four phosphorus sources were added to the experimental group, as follows: (1) $\mathrm{Ca}_{3}\left(\mathrm{PO}_{4}\right)_{2}$ at $5 \mathrm{~g}$; (2) lecithin at $0.6 \mathrm{~g}$ and $\mathrm{CaCO}_{3}$ at $5 \mathrm{~g}$; (3) $\mathrm{AlPO}_{3}$ at $4 \mathrm{~g}$; and (4) $\mathrm{FePO}_{4} \cdot 4 \mathrm{H}_{2} \mathrm{O}$ at $7.2 \mathrm{~g}$, respectively. They were respectively placed in triangle bottles with the liquid content of $50 / 250 \mathrm{~mL}$, and the inoculating amount was $2 \%$. Then, these bottles were placed on a rotary shaker at $180 \mathrm{rpm}$ and at $28{ }^{\circ} \mathrm{C}$ for 4 days. The supernatant was 
collected by centrifugation, and the available phosphorus content was determined by the molybdenum blue coloration method [27]. Three replicates were made in each test. The difference between the experimental group and the corresponding control group was determined using Microsoft Excel.

\subsection{Low Molecular Weight (LMW) Organic Acids Derived from the Culture Liquor}

To test the evolution of the $\mathrm{pH}$ of the fermented fungal suspension liquor, a modified liquid Martin medium was prepared with the addition of $1.15 \% \mathrm{NaCl}$. The initial inoculum dosage was set up at $5 \%$ (v/v) to a volume of $150 \mathrm{~mL}$ in $250 \mathrm{~mL}$ containers, which was then incubated at $28 \pm 1{ }^{\circ} \mathrm{C}$ at a rotation speed of $160 \mathrm{rpm}$. The $\mathrm{pH}$ was measured every $24 \mathrm{~h}$ with triplicates for the treated and control groups.

The GC-TOF-MS approach was applied to quantify the major LMW organic acids (oxalic, succinic, and malic acids) produced by $A$. jiangsuensis SM-1 out of the fermentation liquor. After 7 days of incubation, the suspended mycelia were filtered prior to the methyl esterification and extraction of three acids. Preparation of standard solutions: benzoic acid standard solution was prepared by adding $2 \mathrm{~g}$ benzoic acid into $20 \mathrm{~mL}$ methanol; succinic, oxalic, and malic acid standard solutions were prepared by dissolving $2 \mathrm{~g}$ oxalate acid, $0.1 \mathrm{~g}$ succinic acid, and $0.1 \mathrm{~g}$ malic acid and diluting with water $(250 \mathrm{~mL})$. Methyl esterification and extraction: the filtered test solution and all standard solutions were mixed with $1 \mathrm{~mL}$ benzoic acid and $50 \mathrm{~mL}$ of $10 \%$ sulfuric acid-methanol $(v / v)$ solution, and the mixtures

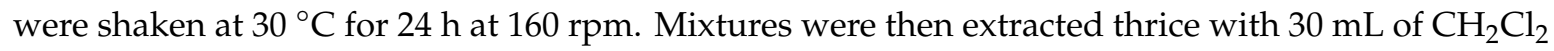
each time, and the extractions were pooled and washed with $50 \mathrm{~mL}$ of saturated $\mathrm{NaCl}$ solutions twice. The extracted liquors were mixed with $25 \mathrm{~g} \mathrm{Na}_{2} \mathrm{SO}_{4}$ and left over the night before filtration. The solvent of filtered solutions was removed with the rotary evaporator, and then, the residues were dissolved with $5 \mathrm{~mL}$ of $\mathrm{CH}_{2} \mathrm{Cl}_{2}$ for $\mathrm{GC}$ analysis. TOFMS conditions: EI source electron energy of $70 \mathrm{eV}$, electron multiplier voltage of $1976 \mathrm{~V}$, the quality of the scan range was 30-550 m/z, ion source temperature of $210{ }^{\circ} \mathrm{C}$, quadrupole temperature of $150{ }^{\circ} \mathrm{C}$, and the collected spectra were retrieved with the Nist02 library. GC conditions: column: HP-5C (30 $\mathrm{m} \times 0.25 \mathrm{~mm} \times 0.25 \mu \mathrm{m})$; injection volume: $1 \mu \mathrm{L}$, split (10:1); inlet temperature: $250{ }^{\circ} \mathrm{C}$; carrier gas: $\mathrm{N}_{2}$; programmed temperature at $40^{\circ} \mathrm{C}$ holding $2 \mathrm{~min}$, and then raised at a rate of $5{ }^{\circ} \mathrm{C} / \mathrm{min}$ to $240{ }^{\circ} \mathrm{C}$, maintained $2 \mathrm{~min}$, detector: FID; detector temperature: $300{ }^{\circ} \mathrm{C}$.

\section{Results}

\subsection{Phylogenetic Analyses}

The topologies of each single-gene and the two-gene (ITS, 28S rDNA) trees were similar. Therefore, we show only the two-gene combined tree. According to the phylogenetic result, the Apophysomyces genus was separated into four main clades with high statistical support. Clade $1(\mathrm{ML} / \mathrm{BI}=100 / 1)$ contains $A$. variabilis and $A$. elegans, whereas clade $2(\mathrm{ML} / \mathrm{BI}=89 / 0.96)$ was clustered with $A$. trapeziformis, A. mexicanus, and A. ossiformis. A. thailandensis was assigned to clade $3(\mathrm{ML} / \mathrm{BI}=100 / 1)$. A. jiangsuensis was clearly separated from the other Apophysomyces species and formed an independent lineage (clade 4) with high statistical support (ML/BI = 100/1). A. jiangsuensis is phylogenetically recognized as a novel species (Figure 1).

The ITS-28S rDNA combined genetic distance between A. jiangsuensis and other Apophysomyces species ranged from $8 \%$ to $12.10 \%$. This genetic distance was more than $3 \%$, which indicated that this fungus is a new species [28].

\subsection{Taxonomy}

Apophysomyces jiangsuensis Siyu Li and Pei Qin, sp. nov.

MycoBank No.: MB 837380.

Etymology: from 'jiangsuensis', which refers to Jiangsu, where the soil containing the new fungus was collected.

Holotype: China, Jiangsu Yancheng Wetland National Nature Reserve of Rare Birds, mudflats of Spartina alterniflora (3336’ E, 120³6’ N), 1 April 2009, Ruiming Han. (Holotype-CGMCC3.17001). 


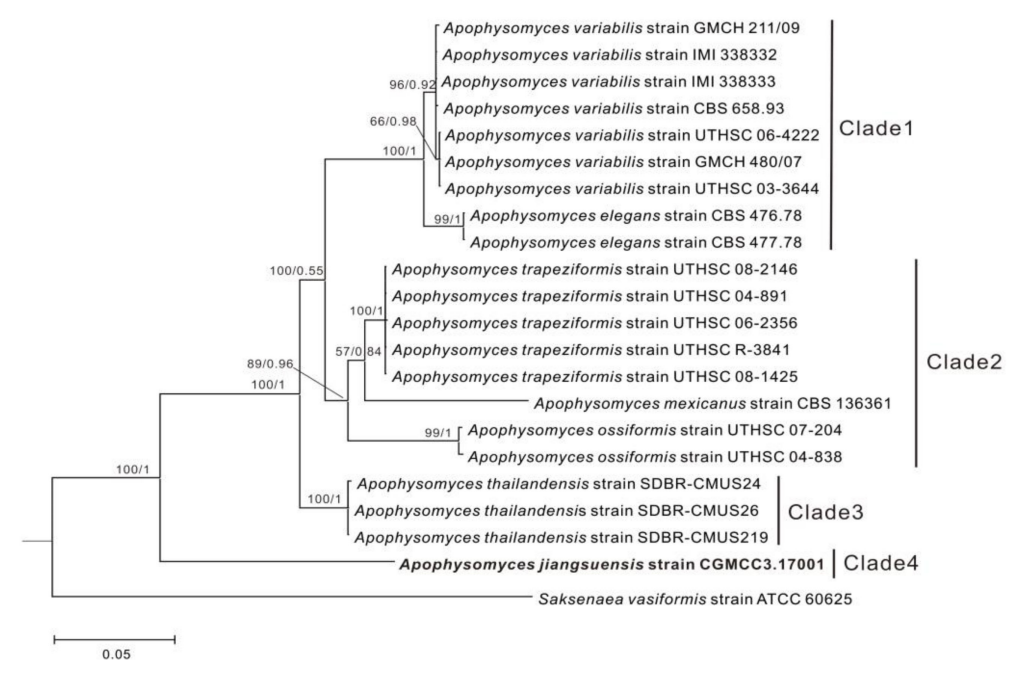

Figure 1. Phylogenetic tree derived from Bayesian inference (BI) and maximum likelihood (ML) analysis of a combined ITS and 28S rDNA sequences. Saksenaea vasiformis was used as an outgroup.

Gene sequences (from holotype): KF048102 (ITS), KF055451 (28s rDNA).

Diagnosis: Differs from other Apophysomyces species in having spherical rather than pyriform sporangia and the spore wall is ornamented rather than smooth.

Description: Colonies were fast growing on MAM and PDA medium with $1.15 \% \mathrm{NaCl}$, flocculent mycelium. The color of the strain was creamy on top and whitish-brown underneath, the edges were smooth and had no odor, and the reverse was brown (Figure 2a,b). On the MEA medium, the strain had the aroma of mushrooms. On OMA and SDA media, the growth was poor, and the edges were uneven, showing significant nutritional deficiencies. It did not grow on CZA medium (Table 2). Sporangiophores were erect, arising singly, unbranched and white with lengths of 40-100 $\mu \mathrm{m}$, and the top of these sporangiophores formed the apophyses (Figure 2c). Under conditions with sufficient nutrients, 1-5 mycelia were produced, while under nutrient-deficient conditions, spores were produced (Figure 2d). Branching hyphae often had a septate basal segment resembling the "foot cell" (Figure 2e). False roots were thin-walled, white, and predominantly unbranched. Sporangia were multispored, small, nearly sphere, peach-shaped with diameters of 10-17 $\mu \mathrm{m}$, when mature with distinct apophyses (Figure 2c). Spores formed on the top of these apophyses and were ellipsoidal with diameters of 4-5 $\times 6-7 \mu \mathrm{m}$ and had raised white nubbins on surface (Figure 2f). The strain grew well in the salinity range of $0.8 \%-1.3 \%$ (Figure 3) and good growth at $28{ }^{\circ} \mathrm{C}$, but growth was sparse and slow at $20^{\circ} \mathrm{C}$, $24{ }^{\circ} \mathrm{C}, 32^{\circ} \mathrm{C}$, and $37^{\circ} \mathrm{C}$ and hardly grew at $10{ }^{\circ} \mathrm{C}$ and $42{ }^{\circ} \mathrm{C}$.

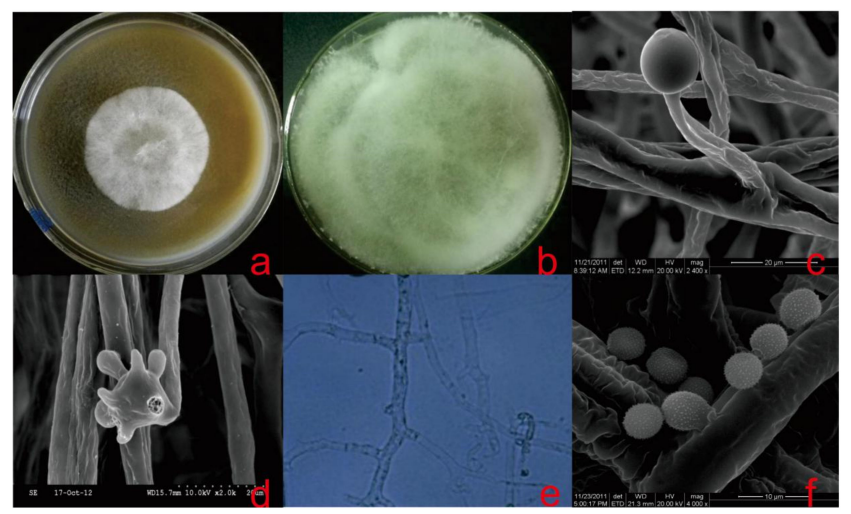

Figure 2. Apophysomyces jiangsuensis. (a) Fungal colony after $72 \mathrm{~h}$ on PDA; (b) covered the Petri dish after 5 days on MAM; (c) sporangiophores and sporangia; (d) forming spores and hyphae; (e) septum in the hypha; and (f) spores. 
Table 2. Growth characteristics of $A$. jiangsuensis on different media.

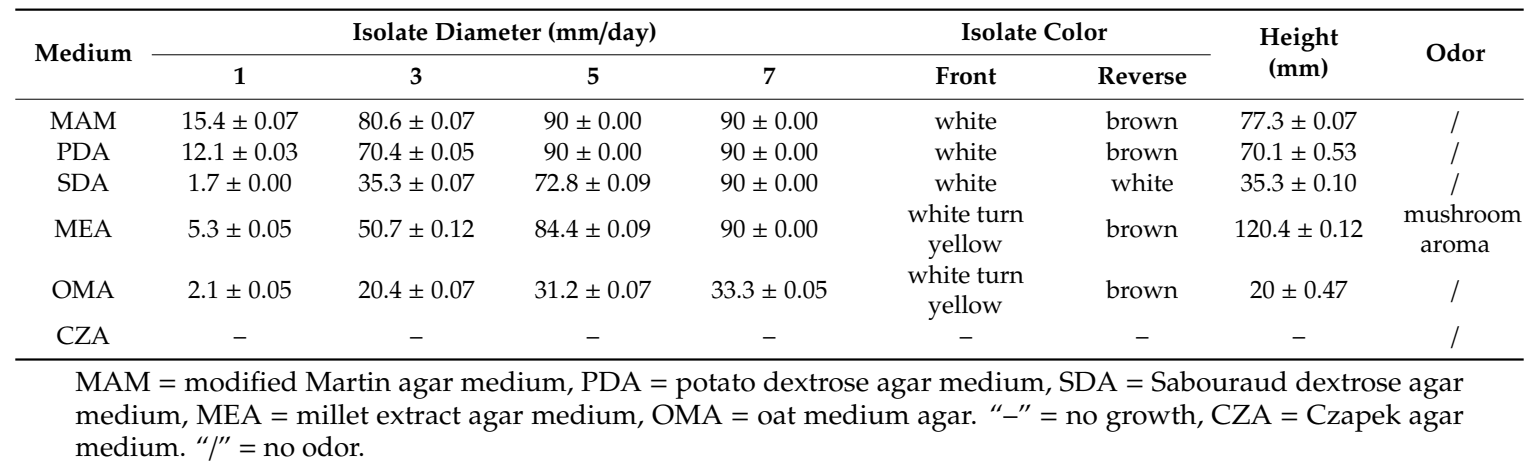

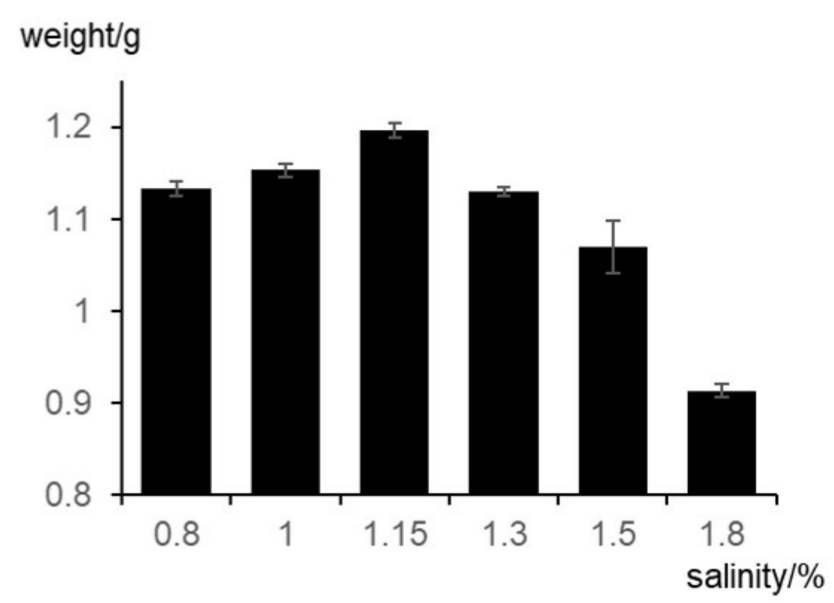

Figure 3. The effect of different salinity on biomass.

Notes: The colony of A. jiangsuensis isolated from salt marsh had seemingly identical characteristics to those from species of the previous genus Apophysomyces [1], which possessed false roots, flocculent mycelia, and a small amount of diaphragm. The colony appeared white first before turning brown. It had difficulty forming spores in a normal medium. A significant difference existed in microscopic structures. The sporangia of known Apophysomyces species were typically pyriform in shape and spores were smooth-walled, whereas the sporangia of $A$. jiangsuensis were nearly spherical, peach-shaped. The spores were ellipsoidal and had raised white nubbins on the surface. As with other species of Apophysomyces, A. jiangsuensis failed to sporulate on routine mycological media. To stimulate the production of spores, a special culture was made using millet and bran solid medium (MBM) at $28+1{ }^{\circ} \mathrm{C}$ for 7 days.

\subsection{The Phosphate-Solubilizing Ability}

In comparison with the control group, A. jiangsuensis cultured in liquid medium with $1.15 \%$ $\mathrm{NaCl}$ had an obvious decomposition effect on three kinds of phosphorus sources, namely, lecithin, $\mathrm{Ca}_{3}\left(\mathrm{PO}_{4}\right)_{2}$, and $\mathrm{AlPO}_{3}$; and the available phosphorus concentrations were $16.60,13.60$, and $15.50 \mathrm{mg} / \mathrm{L}$, respectively. However, it had no obvious decomposition effect on $\mathrm{FePO}_{4} \cdot 4 \mathrm{H}_{2} \mathrm{O}$ (Figure 4).

\section{4. pH Dynamics of the Culture Liquor}

During the 7-day culture of $A$. jiangsuensis, the $\mathrm{pH}$ of the fermented liquid progressively declined from 6.85 at the beginning to 2.27 at the end, compared with 6.45 in the medium without inoculation (Figure 5). A rapid decline was observed from days 2 to 4 , whereas a significant difference existed between the control and inoculated groups $(p<0.01)$, indicating a strong effect of the strain on the medium $\mathrm{pH}$ value. 

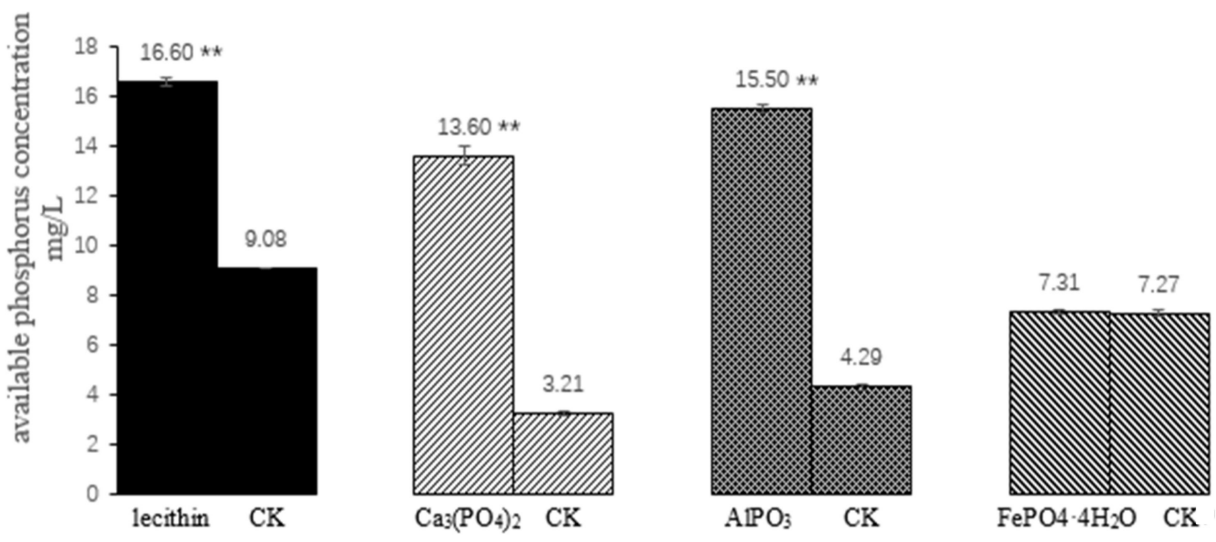

phosphorous source

Figure 4. The ability of the strain to disintegrate phosphorus from different sources. ${ }^{* *}$ showed significant difference between the treatment group and the control group after a $t$ test $(p<0.01)$.

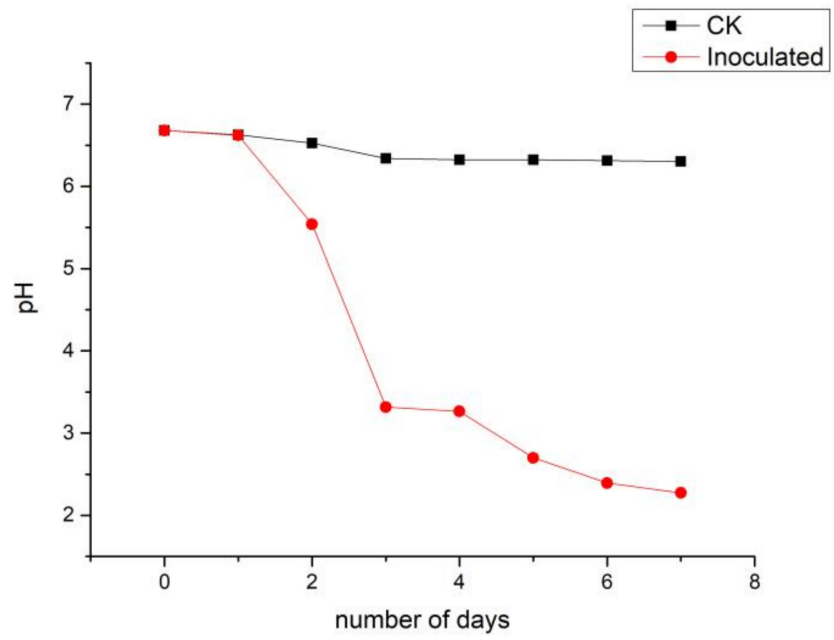

Figure 5. $\mathrm{pH}$ of the culture liquid during a 7-day incubation of A. jiangsuensis in the culture medium.

\subsection{LMW Organic Acids Derived from the Culture Liquor}

TOFMS analysis identified that the LMW organic acid species collected in the culture liquor included oxalic, succinic, and malic acids and a trace of citric acid. According to the standard curve regression equation, the concentrations of the measurable organic acids were as follows: oxalic acid, $652.50 \mathrm{mg} / \mathrm{L}$; succinate, $9.14 \mathrm{mg} / \mathrm{L}$; and malic acid, $3.16 \mathrm{mg} / \mathrm{L}$, respectively (Figure 6). When mixing standard acid samples at the above concentrations with non-inoculated medium, the $\mathrm{pH}$ of the medium was 2.88 on average.

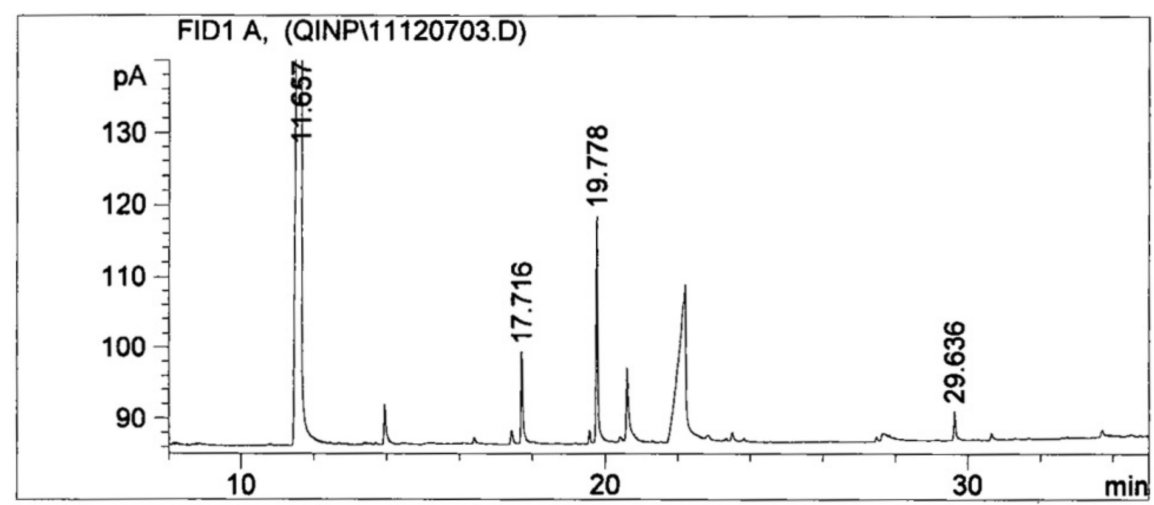

Figure 6. Sample organic acid methyl ester by gas chromatogram. 


\section{Discussion}

A newly isolated phosphate-solubilizing fungus from the topsoil of S. alterniflora habitats in Yancheng coastal salt marsh was identified by morphological characteristics and phylogenetic analyses. Colony and spores' morphologies are the major bases for the taxonomic identification of fungi in this group. Morphologically, the A. jiangsuensis colony shows identical features with those from the genus Apophysomyces, which has been described previously, based on naked eye observations [1]. However, significant differences in sporangia and spores were observed on a microscopic scale. The sporangia of known Apophysomyces species are typically pyriform in shape and spores are smooth-walled [9]. By contrast, the sporangia of $A$. jiangsuensis are nearly spherical, peach-shaped. The spores are ellipsoidal and have raised white nubbins on the surface. As with other species of Apophysomyces, A. jiangsuensis failed to sporulate on routine mycological media, on sterilized distilled water [19], and on Sabouraud dextrose agar. It was transferred to plates containing sterile distilled water with $0.2 \mathrm{~mL}$ of $10 \%$ yeast extract solution that was filter sterilized [29]. To stimulate the production of spores, a special culture was performed on MBM solid medium at $28+1{ }^{\circ} \mathrm{C}$ for 7 days.

Bonifaz et al. (2014) divided Apophysomyces into two main clades using a phylogenetic tree derived from maximum likelihood analysis of a combined ITS, 28S rDNA, and histone 3 (H3) genes and the described a novel species $A$. mexicanus, which was placed between $A$. ossiformis and A. trapeziformis [10]. Khuna et al. (2019) separated Apophysomyces into three main clades, and A. thailandensis formed the clade III as a novel species [11]. In the current study, the topology of the phylogenetic tree was similar to that described in Bonifaz et al. (2014) and Khuna et al. (2019) [10,11], although only ITS and 28S rDNA sequences were used to construct the current phylogenetic tree. Moreover, A. jiangsuensis formed a distinct clade in this study as in previous studies and was at a great genetic distance from other Apophysomyces species, which clearly indicated that this fungus is a novel species.

The productivity of coastal tidal flat vegetation was believed to be limited by nitrogen, but the growth of the nitrogen-fixing microorganism in plant roots was found to be limited by phosphorus. Therefore, increasing the available phosphorus content in coastal tidal flat soil would effectively increase the nitrogen supply of plants and thus increase the crop yield [30]. A. jiangsuensis grows well in a salinity range of $0.8 \%-1.3 \%$ and can effectively improve the available phosphorus content, because it can decompose inorganic phosphorus compounds and organophosphorus compounds, such as lecithin, $\mathrm{Ca}_{3}\left(\mathrm{PO}_{4}\right)_{2}$, and $\mathrm{AlPO}_{3}$. Thus, it is an excellent phosphorus solubilizer for salinity. This finding is similar to those obtained by previous studies on $A$. thailandensis, which can solubilize different insoluble minerals ( $\mathrm{Ca}, \mathrm{Co}, \mathrm{Fe}, \mathrm{Mn}, \mathrm{Cu}$, and Zn-containing minerals) [18]. However, A. jiangsuensis has no obvious effect on the decomposition of $\mathrm{FePO}_{4} \cdot 4 \mathrm{H}_{2} \mathrm{O}$, which was possibly because the inorganic acids or organic acids produced by the fungus have low solubility in insoluble ferrite.

The fermentation process of PSMs tends to lower the $\mathrm{pH}$ level of the fermentation liquor. The rapid decline of $\mathrm{pH}$ during days $2-4$ suggested the existence of a logarithmic growth phase period of $A$. jiangsuensis, during which the fungus experienced the highest rate of grow and division while organic acid secretion was maximized. The average $\mathrm{pH}$ at day 7 was low (2.27), showing that A. jiangsuensis created a conducive environment for survival under alkaline saline conditions and for it to become the dominant fungal species. Moreover, it decomposes the surrounding phosphates into free forms to promote plant growth. The undergoing mechanism can be simplified as follows: (1) The phosphorus absorbed by plants promotes the increase of the rhizospheric organic fertilizer from exudation and die-back of fine roots. (2) Organic fertilizer stimulates growth and reproduction of various PSMs. (3) Acidification of the microenvironment is elevated due to these microorganisms. (4) The solubilization of insoluble phosphates and other mineral nutrients was accelerated. Out of the LMW organic acids secreted by A. jiangsuensis, oxalic acid is the most considerable quantitatively. Oxalic acid can dissolve lecithin, $\mathrm{Ca}_{3}\left(\mathrm{PO}_{4}\right)_{2}, \mathrm{AlPO}_{3}$, and others and is known to form complexation with or chelate with metal ions, such as aluminum, iron, calcium, and magnesium to release phosphorus [31]. Oxalic acid is one of the simplest organic dicarboxylic acids and is known for its superior ability to dissolve rock phosphate after citric acid. Thus, $A$. jiangsuensis nearly has the most efficient substance to 
neutralize alkaline substances and to mobilize phosphates in the surrounding substrate. Thus, it is especially suited to survive in and to ameliorate salt marsh habitats. The simulation of acidification effect using pure LMW acids resulted in a $\mathrm{pH}$ of 2.88, which was not far from the detected value of 2.27 in fermented liquor, indicating that $A$. jiangsuensis-secreted organic acids play an important role in $\mathrm{P}$ solubilization. The simulated condition had a $\mathrm{pH}$ value that was higher by 0.61 compared with fermentation liquor, which can be attributed to the putative incomplete esterification of organic acids during extraction and/or the existence of other undetected trace organic contents. These factors may lead to the lower measured contents of organic acids compared with the real values, or the fermentation process contained other auxiliary supplement $\mathrm{H}+$ mechanism.

In conclusion, a combination of morphological characteristics and phylogenetic analysis strongly supports the proposal that the fungus is a new species. A. jiangsuensis excretes large amounts of organic acids and creates a conducive environment. On the one hand, it is especially suited to survive in and to ameliorate salt marsh habitats. On the other hand, it can decompose the surrounding phosphates into free forms to promote plant growth. Thus, it is an excellent phosphorus solubilizer for salinity. This study is of great importance for the development of a phosphorus solubilizer to ameliorate soil phosphorous nutrition and to improve the limited plant productivity in the tidelands.

Author Contributions: Conceptualization, P.Q. and F.Z.; methodology, S.L.; software, S.L.; validation, R.H., H.Z. and Y.S.; formal analysis, S.L.; investigation, R.H.; resources, P.Q. and F.Z.; data curation, H.Z.; writing —original draft preparation, S.L.; writing—review and editing, S.L.; visualization, S.L.; supervision, P.Q.; project administration, F.Z. All authors have read and agreed to the published version of the manuscript.

Funding: This research was funded by the National Key R\&D Program of China, grant number 2017YFC0506005; the National Natural Science Foundation of China, grant number 41773081.

Conflicts of Interest: The authors declare no conflict of interest.

\section{References}

1. Misra, P.C.; Srivastava, K.J.; Lata, K. Apophysomyces, a new genus of the Mucorales. Mycotaxon 1979, 8, 377-382.

2. Benny, G.L.; Humber, R.A.; Morton, J.B. Zygomycota: Zygomycetes. In The Mycota; McLaughlin, D.J., McLaughlin, E.G., Lemke, P.A., Eds.; Systematics and Evolution: 113-146; Springer: Berlin, Germany, 2007; Volume VIIA.

3. Hoffmann, K.; Pawłowska, J.; Walther, G.; Wrzosek, M.; de Hoog, G.S.; Benny, G.L.; Kirk, P.M.; Voigt, K. The family structure of the Mucorales: A synoptic revision based on comprehensive multigene-genealogies. Persoonia 2013, 30, 57-76. [CrossRef]

4. Wijayawardene, N.N.; Hyde, K.D.; Al-Ani, L.K.T. Outline of Fungi and fungus-like taxa. Mycosphere 2020, 11, 1060-1456. [CrossRef]

5. Cooter, R.D.; Lim, I.S.; Ellis, D.H.; Leitch, I.O.W. Burn wound zygomycosis caused by Apophysomyces elegans. J. Clin. Microbiol. 1990, 28, 2151-2153. [CrossRef]

6. Chakrabarti, A.; Ghosh, A.; Prasad, G.S.; David, J.K.; Gupta, S. Apophysomyces elegans: An emerging zygomycete in India. J. Clin. Microbiol. 2003, 41, 783-788. [CrossRef]

7. Kimura, M.; Smith, M.B.; McGinnis, M.R. Zygomycosis due to Apophysomyces elegans: Report of 2 cases and review of the literature. Arch. Pathol. Lab. Med. 1999, 123, 386-390.

8. Reddy, I.S.; Rao, N.R.; Reddy, V.M.; Rao, R. Primary cutaneous mucormycosis (Zygomycosis) caused by Apophysomyces elegans. Indian J. Dermatol. Venereol. Leprol. 2008, 74, 367-370. [CrossRef]

9. Alvarez, E.; Stchigel, A.M.; Cano, J.; Sutton, D.A.; Fothergill, A.W.; Chander, J.; Salas, V.; Rinaldi, M.G.; Guarro, J. Molecular phylogenetic diversity of the emerging mucoralean fungus Apophysomyces: Proposal of three new species. Rev. Iberoam. Micol. 2010, 27, 80-89. [CrossRef] [PubMed]

10. Bonifaz, A.; Stchigel, A.M.; Guarro, J.; Guevara, E.; Pintos, L.; Sanchis, M.; Cano-Lira, J.F. Primary cutaneous mucormycosis produced by the new species Apophysomyces mexicanus. J. Clin. Microbiol. 2014, 52, 4428-4431. [CrossRef] [PubMed]

11. Khuna, S.; Suwannarach, N.; Kumla, J.; Jomkhwan, M.; Nuangmek, W.; Kiatsiriroat, T. Apophysomyces thailandensis (Mucorales, Mucoromycota), a new species isolated from soil in northern Thailand and its solubilization of non-soluble minerals. MycoKeys 2019, 45, 75-92. [CrossRef] [PubMed] 
12. Dumas, M.; Frossard, E.; Scholz, R.W. Modeling biogeochemical processes of phosphorus for global food supply. Chemosphere 2011, 84, 798-805. [CrossRef] [PubMed]

13. Gupta, M.; Kiran, S.; Gulati, A.; Singh, B.; Tewari, R. Isolation and identification of phosphate solubilizing bacteria able to enhance the growth and aloin-A biosynthesis of Aloe barbadensis Miller. Microbiol. Res. 2012, 167, 358-363. [CrossRef]

14. Mehta, P.; Walia, A.; Chauhan, A.; Shirkot, C.K. Plant growth promoting traits of phosphate-solubilizing rhizobacteria isolated from apple trees in trans Himalayan region of Himachal Pradesh. Arch. Microbiol. 2013, 195, 357-369. [CrossRef] [PubMed]

15. Sindhu, S.S.; Phour, M.; Choudhary, S.R.; Chaudhary, D. Phosphorus cycling: Prospects of using rhizosphere microorganisms for improving phosphorus nutrition of plants. Geomicrobiol. Biogeochem. 2014, 39, $199-237$.

16. Dorcas, Z.S.; Julio, C.R.L.; Jeffrey, J.C.; Ayixon, S.R.; Susana, V.D.; Mario, S.; Luz, E.D.B.; Jorge, L.F.M. Soil type affects organic acid production and phosphorus solubilization efficiency mediated by several native fungal strains from Mexico. Microorganisms 2020, 8, 1337. [CrossRef]

17. Zhang, H.S.; Wu, X.H.; Li, G.; Qin, P. Interactions between arbuscular mycorrhizal fungi and phosphate-solubilizing fungus (Mortierella sp.) and their effects on Kostelelzkya virginica growth and enzyme activities of rhizosphere and bulk soils at different salinities. Biol. Fertil. Soils 2011, 47, 543-554. [CrossRef]

18. Zhang, H.S.; Qin, F.F.; Qin, P.; Pan, S.M. Evidence that arbuscular mycorrhizal and phosphate-solubilizing fungi alleviate $\mathrm{NaCl}$ stress in the halophyte Kosteletzkya virginica: Nutrient uptake and ion distribution within root tissues. Mycorrhiza 2014, 24, 383-395. [CrossRef]

19. Ellis, J.J.; Ajello, L. An unusual source of Apophysomyces elegans and a method for stimulating sporulation of Saksenaea vasiformis. Mycologia 1982, 74, 144-145. [CrossRef]

20. Larkin, M.A.; Blackshields, G.; Brown, N.P.; Chenna, R. Clustal W and Clustal X version 2.0. Bioinformatics 2007, 23, 2947-2948. [CrossRef]

21. Nicholas, K.; Nicholas, H. GeneDoc: A tool for editing and annotating multiple sequence alignments. Distributed by the authors. Embnew News 1997, 4, 14.

22. Ronquist, F.; Teslenko, M.; Mark, P.V.D.; Ayres, D.L. MrBayes 3.2: Efficient Bayesian phylogenetic inference and model choice across a large model space. Syst. Biol. 2012, 61, 539-542. [CrossRef] [PubMed]

23. Nguyen, L.T.; Schmidt, H.A.; von Haeseler, A.; Minh, B.Q. IQ-TREE: A fast and effective stochastic algorithm for estimating maximum likelihood phylogenies. Mol. Biol. Evol. 2015, 32, 268-274. [CrossRef]

24. Darriba, D.; Taboada, G.L.; Doallo, R.; Posada, D. jModelTest 2: More models, new heuristics and parallel computing. Nat. Methods 2012, 9, 772. [CrossRef] [PubMed]

25. Hoang, D.T.; Chernomor, O.; Von, H.A.; Minh, B.Q.; Vinh, L.S. UFBoot2: Improving the ultrafast bootstrap approximation. Mol. Biol. Evol. 2017, 35, 518-522. [CrossRef] [PubMed]

26. Tamura, K.; Stecher, G.; Peterson, D.; Filipski, A.; Kumar, S. MEGA6: Molecular Evolutionary Genetics Analysis Version 6.0. Mol. Biol. Evol. 2013, 30, 2725-2729. [CrossRef] [PubMed]

27. Boltz, D.F. Book reviews: Colorimetric determination of nonmetals. Science 1958, 128, 709-710. [CrossRef]

28. Nilsson, R.H.; Kristiansson, E.; Ryberg, M.; Hallenberg, N.; Larsson, K.H. Intraspecific ITS variability in the kingdom Fungi as expressed in the international sequence databases and its implications for molecular species identification. Evol. Bioinform. 2008, 4, 193-201. [CrossRef]

29. Padhye, A.A.; Ajello, L. Simple method of inducing sporulation by Apophysomyces elegans and Saksenaea vasiformis. J. Clin. Microbiol. 1988, 26, 1862-1863. [CrossRef]

30. Sundareshwar, P.V.; Morris, J.T.; Koepfler, E.K. Phosphorus Limitation of Coastal Ecosystem Processes. Science 2003, 229, 563-565. [CrossRef]

31. Mikanova, O.; Novakova, J. Evaluation of the P-solubilizing activity of soil microorganisms and its sensitivity to soluble phosphate. Rostl. Vyrob. 2002, 48, 397-400. [CrossRef]

Publisher's Note: MDPI stays neutral with regard to jurisdictional claims in published maps and institutional affiliations. 